\title{
Baroreflex sensitivity but not microvolt T-wave alternans can predict major adverse cardiac events in ischemic heart failure
}

\author{
Damian K. Kaufmann, Grzegorz Raczak, Małgorzata Szwoch, \\ Elżbieta Wabich, Michał Świątczak, Ludmiła Daniłowicz-Szymanowicz \\ Department of Cardiology and Electrotherapy, Medical University of Gdansk, Poland
}

\begin{abstract}
Background: Major adverse cardiovascular events (MACE) constitutes the main cause of morbidity and mortality in ischemic heart failure (HF) patients. The prognostic value of the autonomic nervous system parameters and microvolt T-wave alternans (MTWA) in this issue has not been identified to date. The aim herein, was to assess the usefulness of the abovementioned parameters in the prediction of MACE in HF patients with left ventricular systolic dysfunction of ischemic origin.

Methods: Baroreflex sensitivity (BRS), heart rate variability (HRV), MTWA and other well-known clinical parameters were analyzed in 188 ischemic HF outpatients with left ventricular ejection fraction $(L V E F) \leq 50 \%$. During 34 (14-71) months of follow-up, 56 (30\%) endpoints were noted.

Results: Univariate Cox analyses revealed BRS (but not HRV), MTWA, age, New York Heart Association functional class III, LVEF, implantable cardioverter-defibrillator presence, use of diuretics and antiarrhythmic drugs, diabetes, and kidney insufficiency were defined as significant predictors of $M A C E$. Pre-specified cut-off values for MACE occurrence for the aforementioned continuous parameters (age, LVEF, and BRS) were: $\geq 72$ years, $\leq 33 \%$, and $\leq 3 \mathrm{~ms} / \mathrm{mmHg}$, respectively. In a multivariate Cox analysis only BRS (HR 2.97, 95\% CI 1.35-6.36, p < 0.006), and LVEF (HR 1.98, 95\% CI 0.61-4.52, $p<0.038)$ maintained statistical significance in the prediction of MACE.

Conclusions: Baroreflex sensitivity and LVEF are independent of other well-known clinical parameters in the prediction of MACE in patients with HF of ischemic origin and LVEF up to 50\%. BRS $\leq 3 \mathrm{~ms} / \mathrm{mmHg}$ and $L V E F \leq 33 \%$ identified individuals with the highest probability of MACE during the follow-up period. (Cardiol J 2022; 29, 6: 1004-1012)
\end{abstract}

Key words: autonomic nervous system, baroreflex sensitivity, heart rate variability, microvolt T-wave alternans, heart failure, left ventricular dysfunction, ischemic cardiomyopathy

\section{Introduction}

Major adverse cardiovascular events (MACE) constitutes the main cause of morbidity and mortality in heart failure (HF) patients, particularly when ischemic etiology is involved [1]. The role and prognostic value of the autonomic nervous system (ANS) indices: baroreflex sensitivity (BRS) and heart rate variability (HRV), as well as microvolt T-wave alternans (MTWA), have been thoroughly confirmed in patients with HF concerning cardiovascular death (CVD) [2-8]. A robust body of the previous data focused on patients with $\mathrm{HF}$ and reduced ejection fraction, which have the most clinical evidence with regard to therapies, and guidelines clearly define management strategies

Address for correspondence: Damian Kaufmann, MD, Department of Cardiology and Electrotherapy, Medical University of Gdansk, ul. Dębinki 7, 80-952 Gdańsk, Poland, tel: +48 5834939 10, fax: +48 5834939 20,

e-mail: d.kaufmann@gumed.edu.pl

Received: 20.03.2020 Accepted: 28.08.2020 Early publication date: 28.09.2020

This article is available in open access under Creative Common Attribution-Non-Commercial-No Derivatives 4.0 International (CC BY-NC-ND 4.0) license, allowing to download articles and share them with others as long as they credit the authors and the publisher, but without permission to change them in any way or use them commercially. 
$[9,10]$. However, the latest recommendations for the management of acute and chronic HF have defined a new category - HF with mid-range ejection fraction (HFmrEF), i.e. with left ventricular ejection fraction (LVEF) in the range of $40-49 \%$. Research on HFmrEF has recently begun to appear, although, data remain scarce and the management is not clearly defined. Estimates show that $\mathrm{HFmrEF}$ is responsible for $13 \%$ to $24 \%$ of all HF cases [11], so from a practical point of view, it seems important to include this group of patients in clinical studies.

The role and prognostic value of ANS indices and MTWA in prediction MACE (which beside CVD involves non-fatal myocardial infarction [MI] and non-fatal stroke), especially in patients with LVEF up to $50 \%$, requires further investigations. In this study, the authors aimed to examine this issue in HF patients with left ventricular systolic dysfunction of ischemic origin.

\section{Methods}

The protocol of the study was approved by the Local Ethics Committee at the Medical University of Gdansk, and written informed consent was obtained from all participants.

\section{Patient's selection}

Between 2009 and 2018, 188 consecutive patients with stable ischemic HF (documented by prior MI, percutaneous coronary intervention, or coronary artery by-pass grafting) and LVEF $\leq 50 \%$ who visited the outpatient clinic, were enrolled in this single-center study. The protocol of the initial visit included anamnesis with particular emphasis on pharmacological treatment and comorbidities; information on the demographic status of the patients; physical examination; two-dimensional-transthoracic echocardiographic study; laboratory blood tests; ANS and MTWA assessment. Additional inclusion criteria were as follows: sinus rhythm; a stable clinical condition for at least 3 months before enrollment; optimal medical therapy for $\mathrm{HF}$ and complete coronary revascularization under current guidelines [9, 12-14]. The exclusion criteria were: age < 18 years; a history of prior sustained ventricular arrhythmia or cardiac arrest; permanent atrial fibrillation/flutter; ventricular paced rhythm due to atrioventricular block; New York Heart Association (NYHA) functional class IV, clinical features of coronary instability; a revascularization (coronary angioplasty and/or surgery by-pass grafting) within 3 months before the study; incomplete coronary revascularization status (scheduled coronarography, coronary angioplasty or surgery by-pass graft); diabetes complicated by documented symptomatic peripheral neuropathy; inability to perform exercise test; poor general condition or non-cardiologic comorbidities with potential unfavorable effect on survival.

\section{Studied parameters}

MTWA assessment. Detailed skin preparation including mild abrasion was performed to reduce the impedance between skin and the electrode and minimize the risk of artifacts. Next, special electrodes (High-Res high-resolution electrodes, Cambridge Heart - Spacelab's Healthcare, Snoqualmie, WA, USA) were placed in three orthogonal Frank leads (X, Y, and Z). The exercise test was performed on a treadmill (Delmar Reynolds), in line with the protocol dedicated for MTWA testing i.e. with a gradual increment in heart rate, first to the range of 100-110 bpm and then to $110-120 \mathrm{bpm}$ for at least $2 \mathrm{~min}$. The data were analyzed with the CH2000 system utilizing a spectral method (Cambridge Heart, Inc., Bedford, MA, USA), and were finally verified by the physician performing the study. The detailed methodology was already precisely described in previous studies $[2,15,16]$. The results of the test were classified as negative (MTWA_neg), positive (MTWA_pos) or indeterminate (MTWA_ind), and additionally, all non-negative results were classified jointly as MTWA_non-neg and were included for further analysis.

ANS assessment. Autonomic parameters were analyzed in a quiet room with dimmed lights between $08.00 \mathrm{am}$ and $1.00 \mathrm{pm}$, all patients were asked to fast (at least $4 \mathrm{~h}$ ) and to refrain from smoking and drinking coffee (at least $12 \mathrm{~h}$ ) before the examination. After adjustment of measuring devices, and a $15 \mathrm{~min}$ stabilization period, resting electrocardiogram (ECG) (Mingograf 720C) and beat-to-beat non-invasive arterial blood pressure (Finapres 2300, Ohmeda) were continuously recorded for 10 min during spontaneous breathing. The collected data were transferred to a PC workstation, processed with POLYAN software [17] and analyzed according to the described protocol $[18,19]$.

The information on RR interval (resolution $1 \mathrm{~ms}$ ) and systolic arterial pressure (SAP) were obtained automatically. BRS (ms/mmHg) was computed by spectral analysis as the average value of the transfer function modulus (Blackman-Tukey method, $0.03 \mathrm{~Hz}$-bandwidth Parzen window) be- 
tween SAP and RR interval time series in low frequency (LF, 0.04-0.15 Hz) band, independently from coherence values [18]. Then, based on collected ECG data routine HRV frequency-domain indices such as LF (in $\mathrm{ms}^{2}$ ), high frequency (HF, $0.14-0.4 \mathrm{~Hz}$, in $\mathrm{ms}^{2}$ ), LF to $\mathrm{HF}$ ratio (LF/HF), and relative spectral powers in LF bands expressed in normalized units (LFnu) were analyzed. Furthermore, time-domain HRV parameters were calculated based on RR data, such as the standard deviation of normal-to-normal $\mathrm{RR}$ intervals ( $\mathrm{SDNN}$ ), the square root of the mean of squared differences between successive intervals (RMSSD), and percentage of adjacent $\mathrm{RR}$ intervals differing by more than $50 \mathrm{~ms}$ (pNN50). Also, the mean heart period (HP in $\mathrm{ms}$ ) value was included in the analysis [20].

\section{Follow-up}

The routine assessment, which took place every 6 months (or earlier if clinically necessary) involved assessing the patient's clinical condition and recorded study if any had occurred. A decision on potential implantation on an implantable cardioverter-defibrillator (ICD) as a primary prevention of sudden cardiac death (or CRT-D if needed) was at the discretion of the physician in charge. The endpoint of the study was 3-point MACE, defined as non-fatal MI, non-fatal stroke and CVD [21, 22]. Non-fatal MI was recognized according to the Fourth Universal Definition of Myocardial Infarction Guidelines [23]. Non-fatal stroke was defined according to the World Health Organization (WHO) definition as rapidly developing clinical signs of focal (or global) disturbance of cerebral function lasting $24 \mathrm{~h}$ (unless interrupted by surgery) with no apparent causes other than of vascular origin [24]. CVD included: fatal stroke or MI; death attributed to HF; any sudden death including unobserved and unexpected death; fatal pulmonary or systemic embolism; death following a vascular operation, vascular procedure, or amputation. All deaths were confirmed against the patient's death certificate information or medical documentation.

\section{Statistical analysis}

Database construction and statistical analysis were performed with STATISTICA 12 software (StatSoft, Poland) and R 2.15.2 environment. Continuous data were presented as the median $\left(25^{\text {th }}-75^{\text {th }}\right.$ percentiles $)$, categorical as a number and percentage. Differences between the $\mathrm{MACE}(+)$ and $\operatorname{MACE}(-)$ groups were calculated with the Mann-Whitney U-test and for qualitative data with the $\chi^{2}$ or Yates $\chi^{2}$ test. The accuracy of pre- specified cut-off values for analyzed parameters was determined by area (AUC) under the receiveroperating characteristic (ROC) curve. An association between the analyzed parameters and the endpoint was assessed using the Cox univariate and multivariate proportional hazard models. The probabilities of reaching the primary endpoint over time, for pre-specified cut-off values for BRS and LVEF, were estimated using the KaplanMeier method and compared with the log-rank test. A p value of less than 0.05 was considered statistically significant.

\section{Results}

Clinical characteristics of the studied patients

Demographic, clinical and echocardiographic data, as well as parameters of the ANS and MTWA of the studied groups, are presented in Table 1 . Briefly, the patients were approximately 64 (58-72) years old, most of them were males (92\%), more than $90 \%$ underwent MI. During 34 (14-71) months of follow-up, 56 (30\%) patients underwent MACE: 7 had a non-fatal stroke, 5 non-fatal MI, and 44 suffered from CVD. These patients were characterized by worse echocardiographic parameters, i.e. lower LVEF and larger atrial size, fewer negative results in MTWA assessment, worse results derived from ANS testing such as lower BRS, LFnu, and LF/HF ratio values. Furthermore, antiarrhythmic and diuretic drugs were used more frequently in these patients, and more often they had diabetes and chronic kidney disease (in stage III or higher).

\section{Predictors of the endpoint}

Univariate Cox analyses revealed age, NYHA III functional class, LVEF, ICD presence, use of diuretics and antiarrhythmic drugs, diabetes and glomerular filtration rate $<60 \mathrm{~mL} / \mathrm{min} / 1.73 \mathrm{~m}^{2}$ as significant predictors of the MACE (Table 2). Only BRS and MTWA_non-neg, but not HRV indices (both time and frequency domain) proved to be statistically significant. Pre-specified cut-off values with a high predictive likelihood for MACE occurrence established by using area under ROC for the aforementioned continuous parameters (age, LVEF, and BRS) were: $\geq 72$ years, $\leq 33 \%$, and $\leq 3 \mathrm{~ms} / \mathrm{mmHg}$, respectively (Table 3 ). In a multivariate Cox analysis, which included all parameters which proved to be statistically significant in the univariate test, only BRS and LVEF maintained statistical significance in the prediction of MACE (Table 2). Figures 1 and 2 presents the Kaplan- 
Table 1. Clinical, laboratory and echocardiographic characteristics of the study group and comparison between the major adverse cardiovascular events $[\mathrm{MACE}(+)$ and $\mathrm{MACE}(-)]$ groups.

\begin{tabular}{|c|c|c|c|c|}
\hline & All $(n=188)$ & $\operatorname{MACE}(+)(n=56)$ & MACE $(-)(n=132)$ & $\mathbf{P}^{*}$ \\
\hline Age [years] & $64(58-72)$ & $65(60-74)$ & $64(58-70)$ & $<0.026$ \\
\hline Male & $173(92 \%)$ & $53(95 \%)$ & $120(91 \%)$ & 0.406 \\
\hline Myocardial infarction & $171(91 \%)$ & $50(89 \%)$ & $121(92 \%)$ & 0.785 \\
\hline Revascularization & $169(90 \%)$ & $53(95 \%)$ & $116(88 \%)$ & 0.195 \\
\hline ICD & $113(60 \%)$ & $37(66 \%)$ & $76(58 \%)$ & 0.262 \\
\hline CRT-D & $17(9 \%)$ & $5(9 \%)$ & $12(9 \%)$ & 1 \\
\hline NYHA class & & & & $<0.001$ \\
\hline NYHA I & $34(18 \%)$ & $3(5 \%)$ & $31(23 \%)$ & \\
\hline NYHA II & $122(65 \%)$ & $36(64 \%)$ & $86(65 \%)$ & \\
\hline NYHA III & $32(17 \%)$ & $17(30 \%)$ & $15(11 \%)$ & \\
\hline \multicolumn{5}{|l|}{ Laboratory parameters } \\
\hline Hemoglobin [g/dL] & $14(13-15)$ & $13.9(13.0-14.5)$ & $14.1(13.3-14.8)$ & 0.368 \\
\hline $\mathrm{BNP}[\mathrm{pg} / \mathrm{mL}]$ & $108(77-300)$ & $238(104-918)$ & $104(66-201)$ & $<0.003$ \\
\hline \multicolumn{5}{|l|}{ Echocardiographic parameters } \\
\hline LADs [mm] & $45(41-48)$ & $46(41-50)$ & $44(40-48)$ & $<0.035$ \\
\hline LVEF [\%] & $33(27-40)$ & $28(23-32)$ & $35(30-42)$ & $<0.001$ \\
\hline \multicolumn{5}{|l|}{ MTWA results } \\
\hline MTWA_neg & $59(31 \%)$ & $10(18 \%)$ & $49(37 \%)$ & $<0.021$ \\
\hline MTWA_pos & $84(45 \%)$ & $32(57 \%)$ & $52(39 \%)$ & $<0.021$ \\
\hline MTWA_ind & $45(24 \%)$ & $14(25 \%)$ & $31(23 \%)$ & $<0.021$ \\
\hline MTWA_non-neg & $129(69 \%)$ & $46(82 \%)$ & $83(63 \%)$ & $<0.010$ \\
\hline \multicolumn{5}{|l|}{ ANS parameters } \\
\hline Mean HP [ms] & $1031(948-1136)$ & 1021 (950-1109) & 1033 (949-1148) & 0.230 \\
\hline SDNN [ms] & $25.3(16.8-37.9)$ & $20.2(11.5-47.0)$ & $25.5(18.8-36.4)$ & 0.229 \\
\hline RMSDD [ms] & $17.1(10.3-29.9)$ & $19.7(7.5-41.4)$ & $16.9(10.9-27.6)$ & 0.470 \\
\hline pNN50 [\%] & $0.68(0-7.9)$ & $0.81(0.0-10.5)$ & $0.63(0.0-6.9)$ & 0.321 \\
\hline LFnu & $51(26.7-69.8)$ & $31.3(23.4-61.6)$ & $54.1(29.5-70.6)$ & $<0.041$ \\
\hline $\mathrm{LF} / \mathrm{HF}$ & $1(0.38-2.31)$ & $0.53(0.3-1.6)$ & $1.2(0.4-2.40$ & $<0.041$ \\
\hline $\mathrm{BRS}[\mathrm{ms} / \mathrm{mmHg}]$ & $4.2(2.2-6.7)$ & $2.6(1.9-4.9)$ & $4.6(2.3-7.8)$ & $<0.001$ \\
\hline \multicolumn{5}{|l|}{ Medications } \\
\hline Beta-adrenolytics & $179(95 \%)$ & $52(93 \%)$ & $127(96 \%)$ & 0.286 \\
\hline ACEI or ARB & $173(92 \%)$ & $52(93 \%)$ & $121(92 \%)$ & 1 \\
\hline Spironolactone/eplerenone & $98(52 \%)$ & $30(54 \%)$ & $68(51 \%)$ & 0.874 \\
\hline Antiplatelet therapy & $171(91 \%)$ & $51(91 \%)$ & $120(91 \%)$ & 1 \\
\hline Statins & $169(90 \%)$ & $52(93 \%)$ & $117(89 \%)$ & 0.596 \\
\hline Digoxin & $6(3 \%)$ & $3(5 \%)$ & $3(2 \%)$ & 0.359 \\
\hline Diuretics & $86(46 \%)$ & $39(70 \%)$ & $50(36 \%)$ & $<0.001$ \\
\hline Anti-arrhythmic & $19(10 \%)$ & $11(20 \%)$ & $8(6 \%)$ & $<0.006$ \\
\hline \multicolumn{5}{|l|}{ Concomitant diseases } \\
\hline Arterial hypertension & $128(68 \%)$ & $35(62 \%)$ & $93(70 \%)$ & 0.313 \\
\hline Diabetes & $51(27 \%)$ & $23(41 \%)$ & $28(21 \%)$ & $<0.012$ \\
\hline GFR $<60\left(\mathrm{~mL} / \mathrm{min} / 1.73 \mathrm{~m}^{2}\right)$ & $41(22 \%)$ & $23(41 \%)$ & $20(14 \%)$ & $<0.001$ \\
\hline Hypercholesterolemia & $128(68 \%)$ & $40(71 \%)$ & $92(67 \%)$ & 0.612 \\
\hline History of atrial fibrillation/flutter & $39(21 \%)$ & $14(25 \%)$ & $25(19 \%)$ & 0.441 \\
\hline Smoking & $139(74 \%)$ & $41(73 \%)$ & $98(74 \%)$ & 1 \\
\hline
\end{tabular}

* $p$ value for comparison between MACE $(+)$ and MACE(-) groups; ACEI - angiotensin-converting enzyme inhibitor; ARB - angiotensin receptor blocker; BNP - B-type natriuretic peptide; BRS - baroreflex sensitivity; CRT-D — implantable cardioverter-defibrillator with cardiac resynchronization therapy; HP - heart period; LADs - left atrium diameter; LFnu - spectral power in low-frequency range expressed in normalized units; LF/HF — LF to high frequency ratio; LVEF — left ventricular ejection fraction; GFR — glomerular filtration rate; ICD — implantable cardioverter-defibrillator; $\mathrm{MI}$ - myocardial infarction; MTWA ind - indeterminate result for microvolt T-wave alternans: MTWA_neg - negative result for microvolt T-wave alternans; MTWA_non-neg — positive and indeterminate results for microvolt T-wave alternans; MTWA_pos — positive result for microvolt T-wave alternans; NYHA — classification according to the New York Heart Association; pNN50 - proportion of successive R-R intervals that differ by more than $50 \mathrm{~ms}$; QRS - QRS complex width; RMSSD - square root of the mean squared difference of successive R-R intervals; SDNN - standard deviation of the average R-R intervals of the sinus rhythm 
Table 2. Univariate and multivariate Cox models estimating the likelihood of major adverse cardiovascular events (MACE).

\begin{tabular}{|c|c|c|c|c|c|c|}
\hline \multirow[t]{2}{*}{ Parameter } & \multicolumn{2}{|c|}{ Unadjusted } & \multirow[t]{2}{*}{$\mathbf{P}^{*}$} & \multicolumn{2}{|c|}{ Adjusted } & \multirow[t]{2}{*}{$\mathbf{P}^{*}$} \\
\hline & HR & $95 \% \mathrm{Cl}$ & & HR & $95 \% \mathrm{Cl}$ & \\
\hline Age $\geq 72$ [years] & 2.03 & $1.17-3.51$ & $<0.012$ & 0.90 & $0.38-2.11$ & 0.801 \\
\hline NYHA class III & 2.02 & $1.14-3.59$ & $<0.016$ & 1.35 & $0.57-3.20$ & 0.327 \\
\hline LVEF $\leq 33[\%]$ & 3.65 & $1.93-6.93$ & $<0.001$ & 1.98 & $0.61-4.52$ & $<0.038$ \\
\hline MTWA_non-neg & 2.15 & $1.08-4.27$ & $<0.029$ & 1.86 & $0.66-5.26$ & 0.242 \\
\hline $\mathrm{BRS} \leq 3.0[\mathrm{~ms} / \mathrm{mmHg}]$ & 3.78 & $1.85-7.73$ & $<0.001$ & 2.97 & $1.35-6.36$ & $<0.006$ \\
\hline Diuretics & 2.38 & $1.34-4.21$ & $<0.003$ & 1.37 & $0.56-2.77$ & 0.410 \\
\hline Diabetes & 1.76 & $1.03-3.00$ & $<0.039$ & 1.78 & $0.77-4.69$ & 0.165 \\
\hline $\mathrm{GFR}<60\left(\mathrm{~mL} / \mathrm{min} / 1.73 \mathrm{~m}^{2}\right)$ & 2.33 & 1.37-3.99 & $<0.002$ & 1.13 & $0.49-2.57$ & 0.778 \\
\hline
\end{tabular}

${ }^{*} \mathrm{p}$ value for comparison between MACE(+) and MACE(-) groups; BRS - baroreflex sensitivity $\mathrm{Cl}$ - confidence interval; LVEF — left ventricular ejection fraction; GFR - glomerular filtration rate; HR — hazard ratio; MTWA_non-neg — positive and indeterminate results for microvolt T-wave alternans; NYHA - classification according to the New York Heart Association

Table 3. Prognostic accuracy of the pre-specified cut-off values for analyzed parameters as the predictors of major adverse cardiovascular events during the follow-up.

\begin{tabular}{lcccccc}
\hline Parameters & AUC (95\% Cl) & \multicolumn{2}{c}{ Characteristics (95\% Cl) } & & \multicolumn{2}{c}{ Predictive value (95\% CI) } \\
& & Sensitivity (\%) & Specificity (\%) & & Positive (\%) & Negative (\%) \\
\hline Age $\geq 72$ [years] & $0.59(0.5-0.68)$ & 81 & 36 & & 76 & 43 \\
LVEF $\leq 33[\%]$ & $0.79(0.72-0.85)$ & 69 & 79 & & 89 & 51 \\
BRS $\leq 3.0[\mathrm{~ms} / \mathrm{mmHg}]$ & $0.65(0.55-0.76)$ & 69 & 64 & & 85 & 41 \\
\hline
\end{tabular}

AUC - area under the curve; BRS - baroreflex sensitivity; $\mathrm{Cl}$ - confidence interval; LVEF — left ventricular ejection fraction

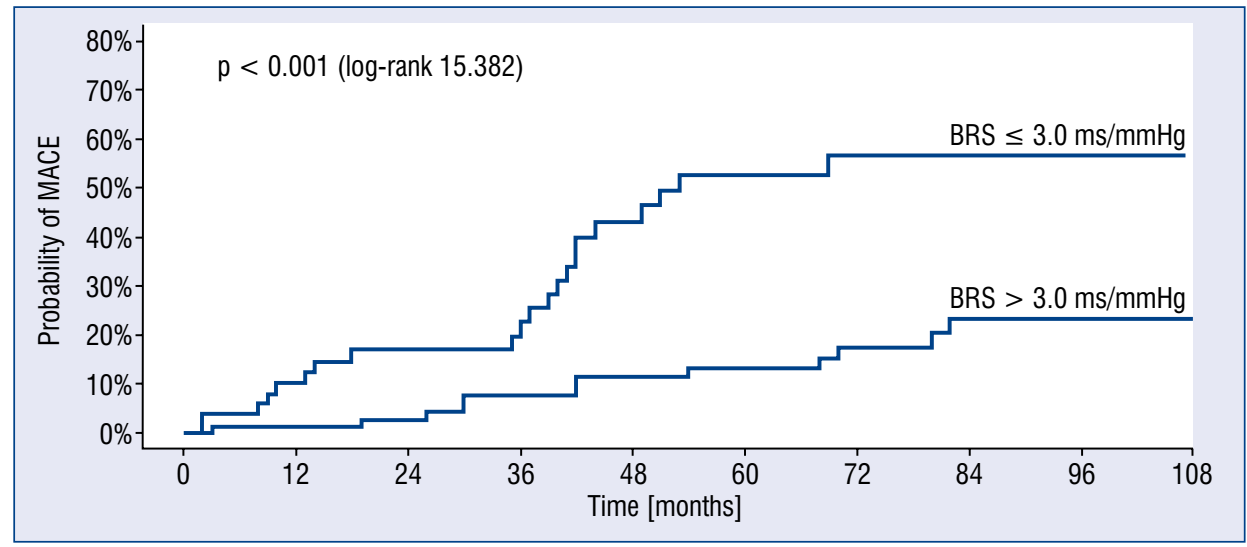

Figure 1. Kaplan-Meier curves illustrating the probability of major adverse cardiovascular events (MACE) during the follow-up period according to the cut-off value for baroreflex sensitivity (BRS).

-Meier curves illustrating the probability of MACE depending on pre-specified cut-off values for LVEF and BRS during the follow-up period, while Figure 3 illustrates the probability of endpoint for a com- bined parameter (LVEF and BRS jointly). As it has been presented, both $\mathrm{LVEF} \leq 33 \%$ and $\mathrm{BRS} \leq 3 \mathrm{~ms} /$ $/ \mathrm{mmHg}$ assessed separately or jointly, can identify patients at highest risk of MACE occurrence. 


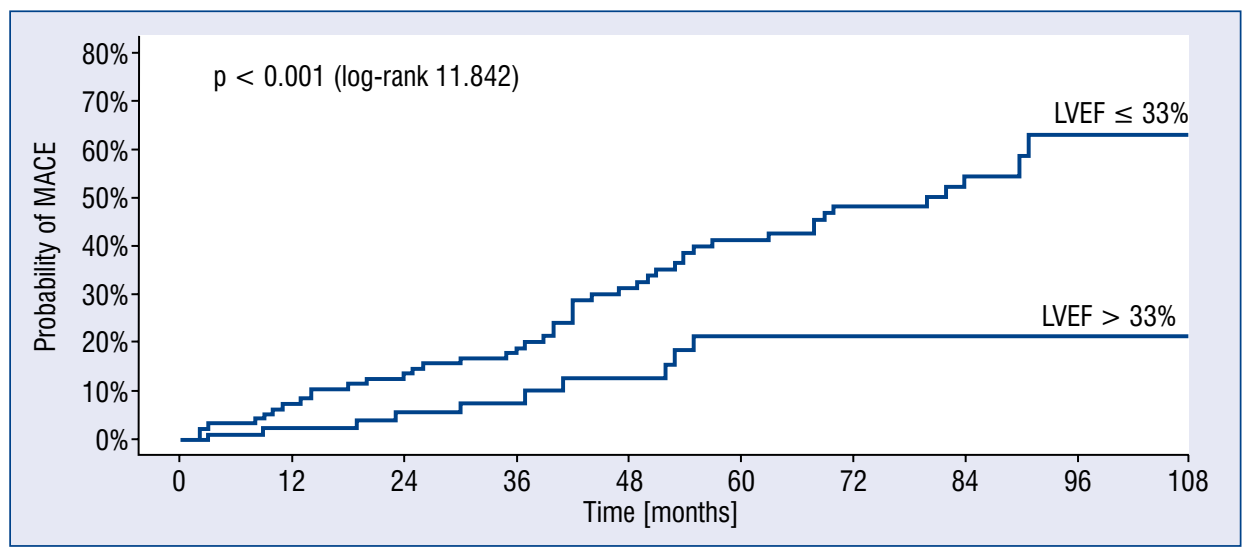

Figure 2. Kaplan-Meier curves illustrating the probability of major adverse cardiovascular events (MACE) during the follow-up period according to the cut-off value for left ventricular ejection fraction (LVEF).

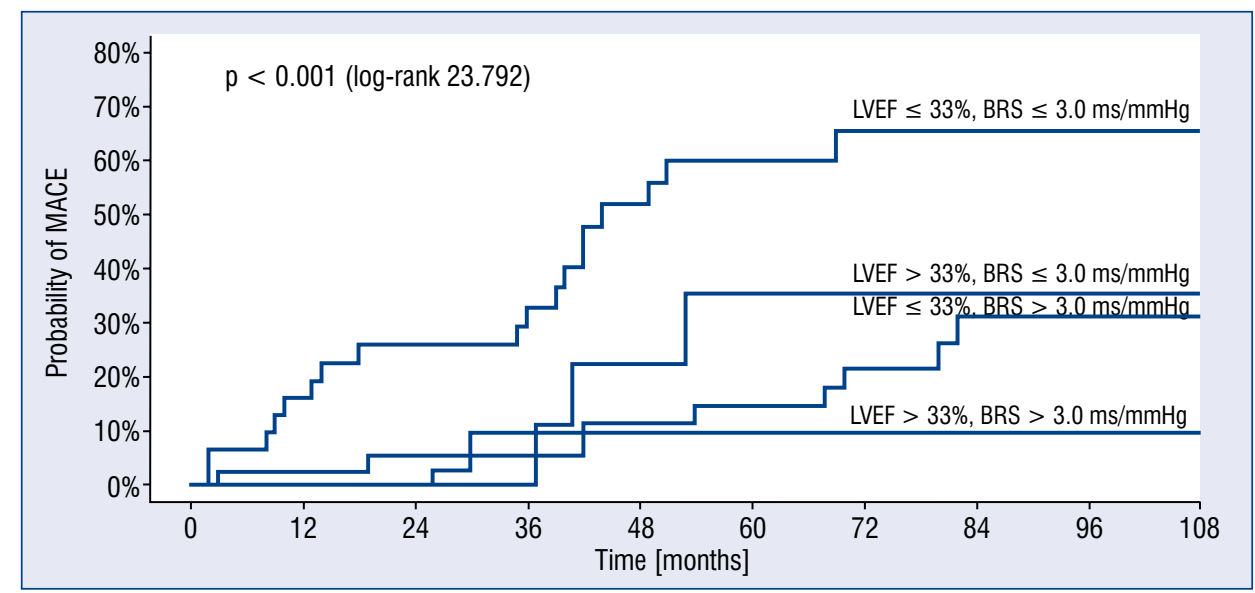

Figure 3. Kaplan-Meier curves illustrating the probability of major adverse cardiovascular events (MACE) during the follow-up period according to the combined parameter (left ventricular ejection fraction [LVEF] + baroreflex sensitivity [BRS]).

\section{Discussion}

The observation that not only LVEF but also $\mathrm{BRS}$ can predict MACE in patients with ischemic left ventricular systolic dysfunction, even after adjusting for other clinical parameters (such as age, NYHA functional class, ICD presence, impaired renal function, diuretics and antiarrhythmic's using, and diabetes), is the principal finding of the present study. The role of MTWA was proved only in univariate Cox analysis. According to available research, this is the first study analyses regarding the usefulness of ANS and MTWA parameters in the identification of high-risk individuals of MACE occurrence among patients with ischemic cardiomyopathy and LVEF up to 50\%. Previous investigations concerning MACE risk assessment among patients with coronary artery disease were dedicated to other well-known clinical parameters [25, 26], which were also confirmed in the present study. The role of ANS indices and MTWA was previously proven for arrhythmic, cardiac and all-cause mortality [2-7, 19, 27-34], however not for MACE, which are common and relevant in this population [1]. Moreover, the vast majority of cited studies omitted patients with ejection fraction $40-50 \%$, who have similarly poor prognosis [35-39].

\section{Prognostic value of MTWA indices in the identification of MACE}

Univariate Cox analysis showed that non-negative MTWA is a prognostic risk factor for MACE occurrence, yet it was not confirmed in the multivariate analysis (Table 2 ). This could be due 
to the fact that abnormal MTWA, as a potential modulator of arrhythmic episodes, is mainly associated with the risk of these events [2, 31, 33, 40-42]. Several studies have shown the usefulness of MTWA in predicting cardiac and overall mortality mainly in patients with reduced $\operatorname{LVEF}[6,7,34$, 43, 44]. However, in MACE, which is a complex endpoint, where the percentage of arrhythmias is relatively smaller, its prognostic value seems to be significantly lower. This was noted by Chow et al. [44], who stated that non-negative MTWA increases the risk of total and arrhythmic mortality but does not increase the risk of non-arrhythmic death. Another explanation may be the interpretation of indeterminate MTWA results. In patients with $\mathrm{LVEF} \leq 35 \%$ indeterminate MTWA is associated with a poor prognosis - similar to the patients with positive MTWA [45]. Regarding the patients with higher LVEF, as it was shown in one of the largest meta-analyses, conducted by Merchant et al. [46], indeterminate MTWA results are not associated with such outcomes.

\section{Prognostic value of ANS indices in the identification of MACE}

In the present study, it was shown in both uniand multivariate Cox analyses, the role of BRS in the prediction of MACE occurrence in patients with $\mathrm{HF}$ of ischemic origin and LVEF up to $50 \%$. The pre-specified cut-off value for BRS $(3 \mathrm{~ms} / \mathrm{mmHg}$ ) is consistent with the results acquired by other researchers, where BRS was determined by both invasive and non-invasive methods $[3,4,19,27$, $28,47]$. In the current study, patients with BRS below $3 \mathrm{~ms} / \mathrm{mmHg}$ had a relative risk for MACE threefold higher than patients above the cut-off. Moreover, as Figure 3 presents, individuals with both $\mathrm{LVEF} \leq 33 \%$ and $\mathrm{BRS} \leq 3 \mathrm{~ms} / \mathrm{mmHg}$ had the highest MACE probability over a 34-month follow-up period. In many previous studies, BRS was proved to have prognostic value in predicting various end-points, such as hospitalization due to HF exacerbation as well as arrhythmic, cardiovascular, or all-cause mortality [3, 4, 8, 19, 27, 28, 47]. The results of our research show that BRS also has an important role in the prediction of MACE, which proves the fact that autonomic imbalance could have an enormous impact on the development of various cardiovascular complications, and that this parameter should be taken into account in risk stratification and clinical evaluation of $\mathrm{HF}$ patients.

Two recently published studies [48, 49], put in question earlier data from the literature regarding the role of autonomic tone parameters. However, the clinical characteristics of studied populations and duration of follow-up periods were different, therefore these results, as it was noticed in the commentary by Parati et al. [50] should be interpreted with caution and should not be extrapolated to HF patients with other clinical characteristics [49].

\section{Limitations of the study}

The authors are well aware of the potential limitations of the study. Firstly, this was a fairly small, single-center study with strict inclusion criteria, and thus needs confirmation in larger trials. Secondly, although the percentage of patients with $\mathrm{HFmrEF}$ is similar to that in the general population of patients with HF, it should be noted that the group of patients with HFmrEF in this article was 50 . Next, due to the nature of the methodology of ANS and MTWA evaluation, only patients with sinus rhythm were included in the study. Moreover, in this paper we primarily focused on the MACE assessment rather than assessing other important endpoints, e.g. hospitalization due to HF exacerbation. Finally, during the follow-up period, ANS or MTWA evaluation was not repeated, which makes it difficult to assess the impact of potential changes occurring at that time.

\section{Conclusions}

Baroreflex sensitivity and LVEF are independent of other well-known clinical parameters (such as age, NYHA functional class, ICD presence, impaired renal function, diuretics and antiarrhythmic's using, and diabetes), in the prediction of MACE in patients with left ventricular systolic dysfunction of ischemic origin and LVEF up to $50 \%$. $\mathrm{BRS} \leq 3 \mathrm{~ms} / \mathrm{mmHg}$ and $\mathrm{LVEF} \leq 33 \%$ identified individuals with the highest probability of MACE during the follow-up period.

\section{Funding}

The research task was financed by the Ministry of Science and Higher Education, awarded for the development of young scientists.

\section{Conflict of interest: None declared}

\section{References}

1. Lavoie L, Khoury H, Welner S, et al. Burden and prevention of adverse cardiac events in patients with concomitant chronic heart failure and coronary artery disease: a literature review. Cardiovasc Ther. 2016; 34(3): 152-160, doi: 10.1111/17555922.12180, indexed in Pubmed: 26915344. 
2. Verrier RL, Klingenheben T, Malik M, et al. Microvolt T-wave alternans physiological basis, methods of measurement, and clinical utility--consensus guideline by International Society for Holter and Noninvasive Electrocardiology. J Am Coll Cardiol. 2011; 58(13): 1309-1324, doi: 10.1016/j.jacc.2011.06.029, indexed in Pubmed: 21920259.

3. Rovere M, Bigger J, Marcus F, et al. Baroreflex sensitivity and heart-rate variability in prediction of total cardiac mortality after myocardial infarction. Lancet. 1998; 351(9101): 478-484, doi: 10.1016/s0140-6736(97)11144-8.

4. La Rovere MT, Maestri R, Robbi E, et al. Comparison of the prognostic values of invasive and noninvasive assessments of baroreflex sensitivity in heart failure. J Hypertens. 2011; 29(8): 1546-1552, doi: 10.1097/HJH.0b013e3283487827, indexed in Pubmed: 21666492.

5. Kleiger RE, Stein PK, Bigger JT. Heart rate variability: measurement and clinical utility. Ann Noninvasive Electrocardiol. 2005; 10(1): 88-101, doi: 10.1111/j.1542-474X.2005.10101.x, indexed in Pubmed: 15649244.

6. Chen Z, Shi Y, Hou X, et al. Microvolt T-wave alternans for risk stratification of cardiac events in ischemic cardiomyopathy: a meta-analysis. Int J Cardiol. 2013; 167(5): 2061-2065, doi: 10.1016/j. ijcard.2012.05.050, indexed in Pubmed: 22683284.

7. Braga SS, Vaninetti R, Laporta A, et al. T wave alternans is a predictor of death in patients with congestive heart failure. Int J Cardiol. 2004; 93(1): 31-38, doi: 10.1016/s0167-5273(03)00119-0.

8. De Ferrari GM, Sanzo A, Bertoletti A, et al. Baroreflex sensitivity predicts long-term cardiovascular mortality after myocardial infarction even in patients with preserved left ventricular function. J Am Coll Cardiol. 2007; 50(24): 2285-2290, doi: 10.1016/j. jacc.2007.08.043, indexed in Pubmed: 18068036.

9. Ponikowski P, Voors A, Anker S, et al. 2016 ESC Guidelines for the diagnosis and treatment of acute and chronic heart failure. Eur J Heart Fail. 2016; 18(8): 891-975, doi: 10.1002/ejhf.592.

10. Priori SG, Blomström-Lundqvist C, Mazzanti A, et al. 2015 ESC Guidelines for the management of patients with ventricular arrhythmias and the prevention of sudden cardiac death: The Task Force for the Management of Patients with Ventricular Arrhythmias and the Prevention of Sudden Cardiac Death of the European Society of Cardiology (ESC). Endorsed by: Association for European Paediatric and Congenital Cardiology (AEPC). Eur Heart J. 2015; 36(41): 2793-2867.

11. Tsuji K, Sakata Y, Nochioka K, et al. CHART-2 Investigators. Characterization of heart failure patients with mid-range left ventricular ejection fraction-a report from the CHART-2 Study. Eur J Heart Fail. 2017; 19(10): 1258-1269, doi: 10.1002/ejhf.807, indexed in Pubmed: 28370829.

12. Fox K, Garcia MA, Ardissino D, et al. Guidelines on the management of stable angina pectoris: executive summary: The Task Force on the Management of Stable Angina Pectoris of the European Society of Cardiology. Eur Heart J. 2006; 27(11): 1341-1381, doi: 10.1093/eurheartj/ehl001, indexed in Pubmed: 16735367.

13. Dickstein K, Cohen-Solal A, Filippatos G, et al. ESC Guidelines for the diagnosis and treatment of acute and chronic heart failure 2008ł. Eur J Heart Fail. 2014; 10(10): 933-989, doi: 10.1016/j. ejheart.2008.08.005.

14. McMurray JJV, Adamopoulos S, Anker SD, et al. ESC Guidelines for the diagnosis and treatment of acute and chronic heart failure 2012: The Task Force for the Diagnosis and Treatment of Acute and Chronic Heart Failure 2012 of the European
Society of Cardiology. Developed in collaboration with the Heart Failure Association (HFA) of the ESC. Eur Heart J. 2012; 33: 1787-847.

15. Daniłowicz-Szymanowicz L, Szwoch M, Dąbrowska-Kugacka A, et al. Usefulness of microvolt T-wave alternans testing in the assessment of all-cause mortality and life-threatening ventricular arrhythmia risk in patients with left ventricular dysfunction. Arch Med Sci. 2015; 11(5): 945-951, doi: 10.5114/aoms.2013.37936, indexed in Pubmed: 26528334.

16. Daniłowicz-Szymanowicz L, Kaufmann D, Rozwadowska K, et al. Microvolt T-wave alternans and autonomic nervous system parameters can be helpful in the identification of low-arrhythmic risk patients with ischemic left ventricular systolic dysfunction. PLoS One. 2018; 13(5): e0196812, doi: 10.1371/journal. pone.0196812, indexed in Pubmed: 29723261.

17. Maestri R, Pinna G. POLYAN: A computer program for polyparametric analysis of cardio-respiratory variability signals. Comput Methods Programs Biomed. 1998; 56(1): 37-48, doi: 10.1016/ s0169-2607(98)00004-2.

18. Pinna GD, Maestri R, Raczak G, et al. Measuring baroreflex sensitivity from the gain function between arterial pressure and heart period. Clin Sci (Lond). 2002; 103(1): 81-88, doi: 10.1042/ cs1030081, indexed in Pubmed: 12095408.

19. Pinna GD, Maestri R, Capomolla S, et al. Applicability and clinical relevance of the transfer function method in the assessment of baroreflex sensitivity in heart failure patients. J Am Coll Cardiol. 2005; 46(7): 1314-1321, doi: 10.1016/j.jacc.2005.06.062, indexed in Pubmed: 16198850.

20. Camm AJ, Bigger JT, Breithardt G, et al. Heart rate variability: Standards of measurement, physiological interpretation, and clinical use. Eur Heart J. 1996; 17(3): 354-381, doi: 10.1093/ oxfordjournals.eurheartj.a014868.

21. Berger A, Simpson A, Bhagnani T, et al. Incidence and cost of major adverse cardiovascular events and major adverse limb events in patients with chronic coronary artery disease or peripheral artery disease. Am J Cardiol. 2019; 123(12): 1893-1899, doi: 10.1016/j.amjcard.2019.03.022, indexed in Pubmed: 31014542.

22. Marx N, McGuire DK, Perkovic V, et al. Composite primary end points in cardiovascular outcomes trials involving type 2 diabetes patients: should unstable angina be included in the primary end point? Diabetes Care. 2017; 40(9): 1144-1151, doi: 10.2337/dc170068, indexed in Pubmed: 28830955.

23. Thygesen K, Alpert JS, Jaffe AS, et al. Fourth universal definition of myocardial infarction (2018). J Am Coll Cardiol. 2018; 72(18): 2231-2264, doi: 10.1016/j.jacc.2018.08.1038, indexed in Pubmed: 30153967.

24. Hatano S. Experience from a multicentre stroke register: a preliminary report. Bull World Health Organ. 1976; 54(5): 541-553, indexed in Pubmed: 1088404.

25. Jernberg T, Hasvold P, Henriksson M, et al. Cardiovascular risk in post-myocardial infarction patients: nationwide real world data demonstrate the importance of a long-term perspective. Eur Heart J. 2015; 36(19): 1163-1170, doi: 10.1093/eurheartj/ehu505, indexed in Pubmed: 25586123.

26. Tsai IT, Wang CP, Lu YC, et al. The burden of major adverse cardiac events in patients with coronary artery disease. BMC Cardiovasc Disord. 2017; 17(1): 1, doi: 10.1186/s12872-0160436-7, indexed in Pubmed: 28052754.

27. Kaufmann D, Raczak G, Szwoch M, et al. Could autonomic nervous system parameters be still helpful in identifying patients 
with left ventricular systolic dysfunction at the highest risk of all-cause mortality? Cardiol J. 2019 [Epub ahead of print], doi: 10.5603/CJ.a2019.0065, indexed in Pubmed: 31257569.

28. La Rovere MT, Pinna GD, Maestri R, et al. Prognostic implications of baroreflex sensitivity in heart failure patients in the beta-blocking era. J Am Coll Cardiol. 2009; 53(2): 193-199, doi: 10.1016/j.jacc.2008.09.034, indexed in Pubmed: 19130988.

29. La Rovere MT, Pinna GD, Maestri R, et al. Short-term heart rate variability strongly predicts sudden cardiac death in chronic heart failure patients. Circulation. 2003; 107(4): 565-570, doi: 10.1161/01. cir.0000047275.25795.17, indexed in Pubmed: 12566367.

30. Farrell TG, Bashir Y, Cripps T, et al. Risk stratification for arrhythmic events in postinfarction patients based on heart rate variability, ambulatory electrocardiographic variables and the signal-averaged electrocardiogram. J Am Coll Cardiol. 1991; 18(3): 687-697, doi: 10.1016/0735-1097(91)90791-7, indexed in Pubmed: 1822090.

31. Costantini O, Hohnloser SH, Kirk MM, et al. The ABCD (Alternans Before Cardioverter Defibrillator) Trial: strategies using T-wave alternans to improve efficiency of sudden cardiac death prevention. J Am Coll Cardiol. 2009; 53(6): 471-479, doi: 10.1016/j.jacc.2008.08.077, indexed in Pubmed: 19195603.

32. Bloomfield D, Bigger J, Steinman R, et al. Microvolt T-wave alternans and the risk of death or sustained ventricular arrhythmias in patients with left ventricular dysfunction. J Am Coll Cardiol. 2006; 47(2): 456-463, doi: 10.1016/j.jacc.2005.11.026.

33. Gehi AK, Stein RH, Metz LD, et al. Microvolt T-wave alternans for the risk stratification of ventricular tachyarrhythmic events: a meta-analysis. J Am Coll Cardiol. 2005; 46(1): 75-82, doi: 10.1016/j.jacc.2005.03.059, indexed in Pubmed: 15992639.

34. Friedman DJ, Bender SR, Markowitz SM, et al. T-wave alternans and ST depression assessment identifies low risk individuals with ischemic cardiomyopathy in the absence of left ventricular hypertrophy. Ann Noninvasive Electrocardiol. 2013; 18(4): 359 -368, doi: 10.1111/anec.12051, indexed in Pubmed: 23879276.

35. Xu HX, Zhu YM, Hua Y, et al. Association between atrial fibrillation and heart failure with different ejection fraction categories and its influence on outcomes. Acta Cardiol. 2019 [Epub ahead of print]: 1-10, doi: 10.1080/00015385.2019.1610834, indexed in Pubmed: 31141463.

36. Cho JH, Choe WS, Cho HJ, et al. Comparison of characteristics and 3-year outcomes in patients with acute heart failure with preserved, mid-range, and reduced ejection fraction. Circ J. 2019; 83(2): 347-356, doi: 10.1253/circj.CJ-18-0543, indexed in Pubmed: 30404976.

37. Shiga T, Suzuki A, Haruta S, et al. Clinical characteristics of hospitalized heart failure patients with preserved, mid-range, and reduced ejection fractions in Japan. ESC Heart Fail. 2019; 6(3): 475-486, doi: 10.1002/ehf2.12418, indexed in Pubmed: 30829002.

38. Rickenbacher P, Kaufmann BA, Maeder MT, et al. Heart failure with mid-range ejection fraction: a distinct clinical entity? Insights from the Trial of Intensified versus standard Medical therapy in Elderly patients with Congestive Heart Failure (TIME-CHF). Eur J Heart Fail. 2017; 19(12): 1586-1596, doi: 10.1002/ejhf.798, indexed in Pubmed: 28295985.

39. Altaie $\mathrm{S}$, Khalife W. The prognosis of mid-range ejection fraction heart failure: a systematic review and meta-analysis. ESC Heart
Fail. 2018; 5(6): 1008-1016, doi: 10.1002/ehf2.12353, indexed in Pubmed: 30211480.

40. Cheng RK, Cox M, Neely ML, et al. Outcomes in patients with heart failure with preserved, borderline, and reduced ejection fraction in the Medicare population. Am Heart J. 2014; 168(5): 721-730, doi: 10.1016/j.ahj.2014.07.008, indexed in Pubmed: 25440801.

41. Amit G, Rosenbaum DS, Super DM, et al. Microvolt T-wave alternans and electrophysiologic testing predict distinct arrhythmia substrates: implications for identifying patients at risk for sudden cardiac death. Heart Rhythm. 2010; 7(6): 763-768, doi: 10.1016/j.hrthm.2010.02.012, indexed in Pubmed: 20156592.

42. Gold MR, Bloomfield DM, Anderson KP, et al. A comparison of T-wave alternans, signal averaged electrocardiography and programmed ventricular stimulation for arrhythmia risk stratification. J Am Coll Cardiol. 2000; 36(7): 2247-2253, doi: 10.1016/ s0735-1097(00)01017-2, indexed in Pubmed: 11127468.

43. Cantillon DJ, Stein KM, Markowitz SM, et al. Predictive value of microvolt T-wave alternans in patients with left ventricular dysfunction. J Am Coll Cardiol. 2007; 50(2): 166-173, doi: 10.1016/j. jacc.2007.02.069, indexed in Pubmed: 17616302.

44. Chow T, Kereiakes DJ, Bartone C, et al. Prognostic utility of microvolt $\mathrm{T}$-wave alternans in risk stratification of patients with ischemic cardiomyopathy. J Am Coll Cardiol. 2006; 47(9): 1820-1827, doi: 10.1016/j.jacc.2005.11.079, indexed in Pubmed: 16682307.

45. Daniłowicz-Szymanowicz L, Suchecka J, Zagożdżon P, et al. Application of microvolt T-wave alternans testing in scheduling implantable cardioverter-defibrillator placement for the primary prevention of sudden cardiac death in patients with left ventricular dysfunction. Kardiol Pol. 2015; 73(6): 429-436, doi: 10.5603/ KP.a2014.0216, indexed in Pubmed: 25371309.

46. Merchant FM, Ikeda T, Pedretti RFE, et al. Clinical utility of microvolt T-wave alternans testing in identifying patients at high or low risk of sudden cardiac death. Heart Rhythm. 2012; 9(8): 1256-64.e2, doi: 10.1016/j.hrthm.2012.03.014, indexed in Pubmed: 22406384.

47. Daniłowicz-Szymanowicz L, Suchecka J, Niemirycz-Makurat A, et al. Autonomic predictors of hospitalization due to heart failure decompensation in patients with left ventricular systolic dysfunction. PLoS One. 2016; 11(3): e0152372, doi: 10.1371/journal. pone.0152372, indexed in Pubmed: 27015089.

48. Pezawas T, Diedrich A, Robertson D, et al. Risk of arrhythmic death in ischemic heart disease: a prospective, controlled, observer-blind risk stratification over 10 years. Eur J Clin Invest. 2017; 47(3): 231-240, doi: 10.1111/eci.12729, indexed in Pubmed: 28102901.

49. Paleczny B, Olesińska-Mader M, Siennicka A, et al. Assessment of baroreflex sensitivity has no prognostic value in contemporary, optimally managed patients with mild-to-moderate heart failure with reduced ejection fraction: a retrospective analysis of 5-year survival. Eur J Heart Fail. 2019; 21(1): 50-58, doi: 10.1002/ ejhf.1306, indexed in Pubmed: 30191647.

50. Parati G, Ochoa JE. Prognostic value of baroreflex sensitivity in heart failure. A 2018 reappraisal. Eur J Heart Fail. 2019; 21(1): 59-62, doi: 10.1002/ejhf.1334, indexed in Pubmed: 30468274. 